\title{
Healthcare professionals' intentions and behaviours: A systematic review of studies based on social cognitive theories Gaston Godin ${ }^{* \dagger 1}$, Ariane Bélanger-Gravel ${ }^{\dagger 2}$, Martin Eccles ${ }^{3}$ and Jeremy Grimshaw ${ }^{4,5}$
}

Address: ${ }^{1}$ Canada Research Chair on Behaviour and Health, Laval University, Québec, Canada, ${ }^{2}$ Research Group on Behaviour and Health, Faculty of Nursing, Laval University, Québec, Canada, ${ }^{3}$ Institute of Health and Society, Newcastle University, Newcastle upon Tyne, UK, ${ }^{4}$ Clinical Epidemiology Program, Ottawa Health Research Institute, Ontario, Canada and ${ }^{5}$ Department of Medicine, University of Ottawa, Ontario, Canada

Email: Gaston Godin* - Gaston.Godin@fsi.ulaval.ca; Ariane Bélanger-Gravel - Ariane.belanger-gravel@fsi.ulaval.ca;

Martin Eccles - martin.eccles@newcastle.ac.uk; Jeremy Grimshaw - jgrimshaw@ohri.ca

* Corresponding author †Equal contributors

Published: 16 July 2008

Implementation Science 2008, 3:36 doi:10.1186/I748-5908-3-36
Received: 7 April 2008

Accepted: 16 July 2008

This article is available from: http://www.implementationscience.com/content/3/1/36

(c) 2008 Godin et al; licensee BioMed Central Ltd.

This is an Open Access article distributed under the terms of the Creative Commons Attribution License (http://creativecommons.org/licenses/by/2.0), which permits unrestricted use, distribution, and reproduction in any medium, provided the original work is properly cited.

\begin{abstract}
Background: There is an important gap between the implications of clinical research evidence and the routine clinical practice of healthcare professionals. Because individual decisions are often central to adoption of a clinical-related behaviour, more information about the cognitive mechanisms underlying behaviours is needed to improve behaviour change interventions targeting healthcare professionals. The aim of this study was to systematically review the published scientific literature about factors influencing health professionals' behaviours based on social cognitive theories. These theories refer to theories where individual cognitions/thoughts are viewed as processes intervening between observable stimuli and responses in real world situations.

Methods: We searched psycINFO, MEDLINE, EMBASE, CIHNAL, Index to theses, PROQUEST dissertations and theses and Current Contents for articles published in English only. We included studies that aimed to predict healthcare professionals' intentions and behaviours with a clear specification of relying on a social cognitive theory. Information on percent of explained variance $\left(R^{2}\right)$ was used to compute the overall frequency-weighted mean $\mathrm{R}^{2}$ to evaluate the efficacy of prediction in several contexts and according to different methodological aspects. The cognitive factors most consistently associated with prediction of healthcare professionals' intention and behaviours were documented.

Results: Seventy eight studies met the inclusion criteria. Among these studies, 72 provided information on the determinants of intention and 16 prospective studies provided information on the determinants of behaviour. The theory most often used as reference was the Theory of Reasoned Action (TRA) or its extension the Theory of Planned Behaviour (TPB). An overall frequency-weighted mean $R^{2}$ of 0.31 was observed for the prediction of behaviour; 0.59 for the prediction of intention. A number of moderators influenced the efficacy of prediction; frequency-weighted mean $R^{2}$ varied from $0.00 \mathrm{I}$ to 0.58 for behaviour and 0.19 to 0.81 for intention.

Conclusion: Our results suggest that the TPB appears to be an appropriate theory to predict behaviour whereas other theories better capture the dynamic underlying intention. In addition, given the variations in efficacy of prediction, special care should be given to methodological issues, especially to better define the context of behaviour performance.
\end{abstract}




\section{Background}

Healthcare professionals are continually exposed to new research findings that could contribute to more effective and efficient patient care. Unfortunately, the transfer of research findings into practice does not happen as readily as desired [1], and many authors have documented gaps between evidence-based practices and the routine clinical practice of healthcare professionals [2,3].

A wide range of factors can influence the clinical practice of healthcare professionals [4], including individual motivational predispositions to change as well as economic, political, and organizational contexts. However, our understanding of these factors and optimal approaches to change healthcare professional behaviour is incomplete. This has led to calls for more theory-based research to better inform the design of interventions to change healthcare professionals' behaviour $[1,5,6]$. Although several theoretical perspectives could be used to explore the determinants of the healthcare professionals' behaviours, most or many clinical practice adoption decisions are individual professional decisions [7]. Consequently, it would be useful to obtain a better understanding of the individual mechanisms of the adoption of new behaviours from social psychology theories [8]. For the purpose of this review, social cognitive theories refer to theories where individual cognitions/thoughts are viewed as processes intervening between observable stimuli and responses in real world situations.

The problem of understanding why healthcare professionals do or do not implement research findings can be viewed as similar to finding out why people in general do or do not adopt a given behaviour such as health-related habits. This has been extensively investigated, and social psychological theories have already demonstrated their value. For the prediction of health-related behaviours, there are several social cognitive theories that predict moderate to large amount of the variance of intention and behaviour [9].

It is surprising that relatively little attention has been given to reviewing published studies applying social cognitive theories investigating healthcare professional behaviours. It is only recently that two publications have reviewed specific aspects of theory-based studies of healthcare professional behaviour and practice. Eccles and colleagues [10] concluded that intention was a valid proxy measure for behaviour among clinicians (i.e., physicians, nurses, pharmacists, other health workers). They did not quantify the strength of association between intention and behaviour among healthcare professionals, but based on the review of ten prospective studies, they concluded that this association was similar in magnitude to that reported for non-professional populations. For example, in a quantitative summary of meta-analyses, Sheeran estimated that, on average, $28 \%$ of the variance in behaviour $\left(\mathrm{R}^{2}\right)$ is accounted for by intentions [11].

A review by Perkins and colleagues [12] was limited to applications of the theories of reasoned action (TRA) [13] and planned behaviour (TPB) [14] to understand clinicians' behaviour (i.e. physicians, nurses, pharmacists, other health workers). They found very few studies ( $\mathrm{N}=$ $19)$, and only half of them $(\mathrm{N}=9)$ included a measure of behaviour (eight self-reported; one objective from medical record). As in the review by Eccles and colleagues [10], they also did not quantify the strength of association between TRA/TPB constructs and actual behaviour, but nonetheless concluded that different constructs of these two theories predict intention and behaviour among different groups of clinicians.

Obviously, more information is needed regarding the usefulness of social cognitive theories to understand and predict healthcare professionals' intentions and behaviours. The aim of this study was to review systematically the literature to quantify to what extent studies based on social cognitive theories explain intention of healthcare professionals to adopt clinical behaviours and predict health professionals' clinical behaviour. Given that any of several social cognitive theories could have been used to investigate healthcare professional behaviours, this review was not limited to applications of the TRA and TPB. Other social theories such as Bandura's social cognitive theory [15], Triandis' theory of interpersonal behaviour [16] and others theories of behaviour were included as well.

\section{Methods \\ Inclusion and exclusion criteria}

We included studies that assessed the predictive value of clearly specified social cognitive theories (e.g., theory of planned behaviour, social cognitive theory, theory of interpersonal behaviour, etc.) for clinician intentions and/or clinical behaviours. It must be mentioned that these theories are considered 'theories of the problem' (i.e., determinants) instead of 'theories of the action' (i.e., change). Clinical behaviours were defined as any behaviour performed in a clinical context. We only included prospective studies focusing on prediction of behaviour, i.e., studies assessing behaviour at a later point in time following the assessment of the theoretical constructs; this was done in order to respect one of the main theoretical assumptions of the majority of the social cognitive theories $[13,17]$. Studies that predicted behaviour instead of intention within a cross-sectional design were excluded. However we did include cross-sectional studies focusing on prediction of intention. Finally, studies aimed at predicting students' behaviours (except for residents in med- 
icine) were excluded because these were not considered clinical-related behaviours.

\section{Literature search}

The literature search was performed between September 14 and October 30, 2007 by ABG. We searched psycINFO (1960-2007), MEDLINE (1966-2007), EMBASE (19742007), CIHNAL (1982-2007), Index to theses (19702007), PROQUEST dissertations \& theses (1960-2007), and Current Contents (2006-2007) for articles published in English only. The search strategy was behaviour OR intention AND [health professionals] (see Additional file 1: The literature search). This was modified as appropriate for the other databases such as MEDLINE and EMBASE. ABG undertook the initial screen of the search results for potentially included studies. ABG and GG then screened potentially included studies against the inclusion criteria. For all included studies, the reference lists were checked manually.

\section{Review methods}

Data about authors and year of publication, population under study, sample size, study design, main theory used, variable predicted (intention/behaviour), kind of behaviour, variables measured, and main results were abstracted by ABG and reviewed by GG; this is summarized in electronic tables (see Additional file 2: Prospective studies aimed at predicting health professionals' behaviour, and Additional file 3: Studies aimed at predicting health professionals' intentions). Duplicate data abstraction was undertaken for $15 \%$ of the dataset by SA. Disagreements were resolved by consensus between ABG, GG and SA. When necessary, we attempted to contact the authors by e-mail for key missing data elements.

Before analyzing the data set, a number of decisions were taken. First, several of the published studies used the same sample to predict different intentions/behaviours. In this situation, we selected at random one of the intention/ behaviour models in order to avoid attributing more weight to such studies. Second, a few studies reported results from application of different theories to the same sample. For the same reason mentioned above, only the model with the highest explained variance was retained for analysis.

For the analysis, we calculated an overall frequencyweighted mean $\mathrm{R}^{2}$ for intentions and behaviours. We also documented the variables measured and the number of times these variables contributed significantly $(p<0.05)$ to the prediction of the dependent variable (i.e., variables most consistently associated with intention or behaviours). These variables were classified according to the theoretical domains defined by Michie and colleagues [8] (see Additional file 4: Classification of variables). How- ever, in order to take into consideration the ethical dimension of healthcare professional behaviours, moral norm was retained as an additional category. Also, although past behaviour and habits are not psychosocial constructs per se, these two factors were retained as another category. In addition, we explored the impact of a number of $a$ priori defined potential moderators by comparing the frequency-weighted mean $\mathrm{R}^{2}$ for different categories of moderators using Fisher's $\mathrm{Z}$ transformation procedure for correlations. A small number of empirical criteria (i.e., moderators) were used to evaluate the efficacy of the studies to predict intention/behaviour. Moderators included: type of professional (e.g., physicians, nurses, pharmacists, etc.); type of behaviour (e.g., prescribing, compliance with guidelines, wearing gloves, perform an examination, etc.); main theory used (e.g., theory of planned behaviour, social cognitive theory, etc); sample size; psychometric qualities; type of dependent variable measurement (objective: direct observation, documentation from databases and behaviour reported from the patients; subjective: self-reported behaviour) and the level of correspondence between intention and behaviour. Based on the work of Rashidian and colleagues [18], we dichotomized the studies in two categories: less than 150 respondents versus 150 and more. For psychometric qualities, we dichotomized internal consistency as good (Cronbach's alpha coefficient of 0.60 or more) versus poor/no information provided [19]. If only partial information was provided, the studies were classified as 'good' if the reported psychometric qualities met the standards. The level of correspondence between intention and behaviour was evaluated according to Fishbein and Ajzen's guidelines [13]; that is, intention and behaviour must correspond in terms of action (e.g., advise to have), target (e.g., retina screening), context (e.g., patients with type 2 diabetes), and time (e.g., during the next three months). Studies for which the measurement of intention and behaviour corresponded in terms of action, target, and context were classified as having a good intentionbehaviour level of correspondence; the time element was not considered.

\section{Results \\ Description of included studies}

Results from the bibliographic screen are presented in Figure 1 . Seventy-six studies ( $N=20,259$ participants) were included in the review. Among these, 16 studies adopted a longitudinal design to predict healthcare professional's behaviours. In addition, 72 of these studies provided information on determinants of intention.

Clinical-related behaviours were investigated in populations of physicians [20-25], nurses [26-32], and other health professionals (i.e., pharmacists [33,34] and psychologists [35]). Among physicians, the behaviours inves- 


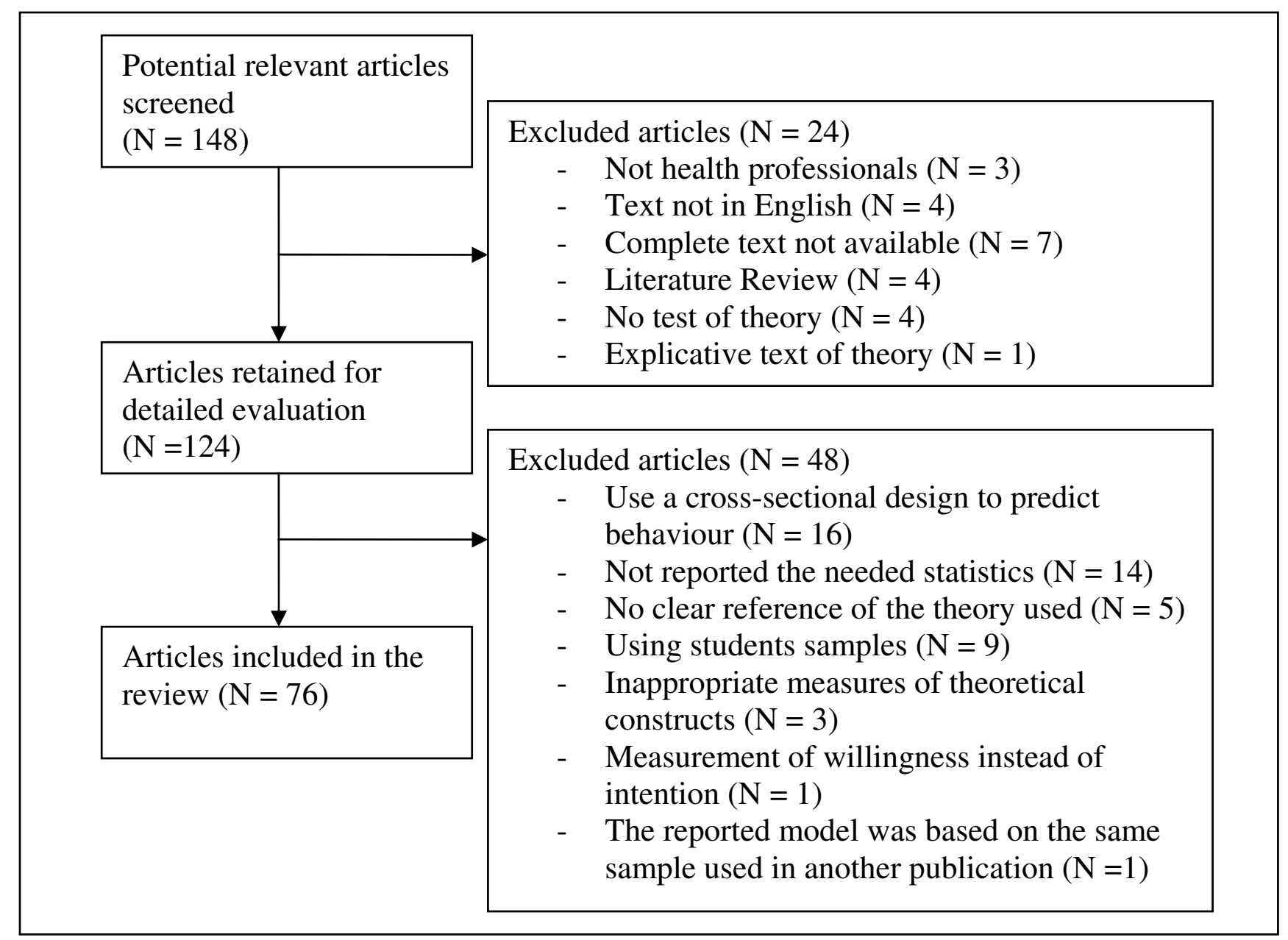

Figure I

The QUORUM statement flow diagram.

tigated were related to clinical practice (e.g., prescribing, performing an examination, referring patients to specialists, etc.) [20-23], compliance with guidelines (e.g., hand hygiene and wearing gloves) [24], and counseling [25]. Among nurses, the behaviours studied were related to clinical practice (e.g., professional support for labour, pain management, providing care to patients, etc.) $[26,30,31]$, compliance with guidelines [27,28], and documentation [29,32]. Clinical practice [35] and counseling $[33,34]$ were also investigated for other professionals.

For the prediction of intention, several studies were also available for the different categories of health professionals: physicians [20,21,23-25,36-59], nurses [26-31,6082], and other clinicians [35,83-95]. Other clinicians included pharmacists $[85,88,90,94]$, dentists [83,95], mental health professionals [86,87], psychologists [35], social workers [91], and a mix of different professions $[84,89,92,93]$. Among studies of physicians' intention, the prediction of intention related to clinical practice (e.g., prescribing, performing an examination, referring patients to specialists, etc.) $[20,21,23,37,38,41,48,49,53$ 55,57-59], acceptance of technologies [40,42,45,46,51], compliance with guidelines (e.g., hand hygiene and wearing gloves) $[24,36,44,50,56]$, counseling [25,39,52], and documentation $[43,47]$. Among nurses, their intentions related to clinical practice (e.g., professional support for labour, pain management, providing care to patients, etc.) [26,30,31,60-64,66-72,74-79,81], acceptance of technologies [65], compliance with guidelines [27,28,73,80,82], and documentation [29]. Clinical practice $[35,83,84,87,91,95]$, compliance with guidelines $[89,92,93]$, and counseling $[85,86,88,90,94]$ were also investigated for other professionals.

\section{Social cognitive models efficacy}

There were important variations in efficacy of prediction of behaviour and intention; the $\mathrm{R}^{2}$ varied from 0.001 to 
0.58 for behaviour and 0.14 to 0.91 for intention. Overall, the frequency-weighted mean $\mathrm{R}^{2}$ for the prediction of behaviour was 0.31 (Number of studies $(\mathrm{N})=15$, number of professionals $(\mathrm{N})=2,112)$ and $0.59(\mathrm{~N}=64, \mathrm{~N}=$ $14,986)$ for the prediction of intention. The overall efficacy of prediction according to the main theory used to guide the studies is presented in Table 1. For the prediction of behaviour, the theory most often used as reference was the TRA or its extension the TPB. Only one study used the operant learning theory (OLT) [96], and another one used the social cognitive theory (SCT) [15]. The predictive power of studies employing the TRA/TPB to predict health professionals' behaviours was significantly better than studies employing the other theories $(\mathrm{Z}=6.085 ; p<$ 0.0001).

For the prediction of intention, the theories most frequently used to guide the studies were, in order of importance, the TRA/TPB, the technology acceptance model (TAM) [97], the theory of interpersonal behaviour (TIB), the OLT and, finally, the attitude, social and self-efficacy model (ASE) [98]. However, among these theories, studies based on the TIB best predicted health professionals' intentions $(Z=12.461 ; p<0.0001, Z=11.287 ; p<0.0001$ and $Z=12.389 ; p<0.0001$ for the comparison with TPB/ TRA, TAM, and the other theories, respectively).

\section{Most consistent variables associated with behaviour and intention}

The number of times the variables were assessed and found to have a significant effect for the prediction of behaviour and intention is presented in Table 2. Among the variables assessed, the cognitive factors most consistently associated with prediction of healthcare professional's behaviours (i.e., at least $50 \%$ of the time) were beliefs about capabilities (sample size-weighted average correlation: $\left.r_{+}=0.18, k=7, N=1,484\right)$, and intention (sample size-weighted average correlation: $r_{+}=0.46, k=$ $11, \mathrm{~N}=1,754)$. Beliefs about consequences, social influ- ences, past behaviour, and knowledge were also reported to be correlates of behaviour, but to a lesser extent. The other variables were not assessed at least three times and no further analysis was performed.

With respect to the factors explaining intention, the most consistently significant cognitive factors (i.e., at least $50 \%$ of the time) were beliefs about capabilities, beliefs about consequences, moral norm, social influences, and social/ professional role and identity. Other determinants frequently reported were past behaviour and emotion. Finally, the less frequently significant variables were socio-demographic characteristics, environmental influences, and knowledge.

\section{Type of professional and behaviour}

The efficacy of the studies using social cognitive theories to explain intention and predict behaviour of healthcare professionals for different types of professionals and behaviours is presented in Table 3. The comparison of the computed frequency-weighted mean $\mathrm{R}^{2}$ between healthcare professional categories indicated that compared to physicians and nurses' behaviours the prediction for other professionals was better $(Z=-5.791 ; p<0.0001$ and $Z=-$ $6.069 ; p<0.0001$, respectively). For the prediction of intention, there were significant differences between the frequency-weighted mean $\mathrm{R}^{2}$ values of all types of professionals (physicians versus nurses: $Z=-13.414 ; p<0.0001$; physicians versus other professionals: $Z=-5.909 ; p<$ 0.0001 ; and nurses versus other professionals: $Z=6.009$; $p<0.0001)$ with the better prediction observed in studies of nurses.

\section{Methodological moderators of the efficacy of prediction} The efficacy of prediction of behaviour and intention according to different methodological moderators is presented in Table 4. The results indicate that the prediction of behaviour and intention was significantly better when sample sizes were equal to or greater than 150 participants

Table I: Overall efficacy of prediction according to the theory used in the studies

\begin{tabular}{lcc}
\hline Main theory used to model... & $\begin{array}{c}\text { Number of } \\
\text { participants } \\
\text { (studies) }\end{array}$ & $\begin{array}{c}\text { Frequency- } \\
\text { weighted mean } \\
\mathrm{R}^{2}\end{array}$ \\
\hline Behaviour & $1,882(14)$ \\
- Theory of planned behaviour (theory of reasoned action) & $230(1)$ & 0.35 \\
- Others* & & 0.06 \\
& & $734(3)$ \\
Intention & $13,188(56)$ & 0.81 \\
- Theory of interpersonal behaviour & $535(2)$ & 0.59 \\
- Theory of planned behaviour (theory of reasoned action) & $529(3)$ & 0.47 \\
- Technology acceptance model & 0.42 &
\end{tabular}

Note: Because there were missing data in few publications, total differs from 16 and 72 studies for the behaviour and intention, respectively.

* Only the study based on the Operant Learning Theory was included; the other study did not provide information on $\mathrm{R}^{2}$. 
Table 2: Variables measured and associated with behaviour and intention

\begin{tabular}{|c|c|c|c|}
\hline \multirow{2}{*}{$\begin{array}{l}\text { Variables measured } \\
\text { Prediction of behaviour }\end{array}$} & \multicolumn{2}{|c|}{ Number of time } & \multirow{2}{*}{$\begin{array}{c}\text { Ratio } \\
(\text { Significant/assessed }) \times 100(\%)\end{array}$} \\
\hline & Assessed & $\begin{array}{l}\text { Significant } \\
(p<0.05)\end{array}$ & \\
\hline Intention & 12 & 6 & 50.0 \\
\hline Beliefs about consequences & 9 & 4 & 44.4 \\
\hline Beliefs about capabilities & 8 & 5 & 62.5 \\
\hline Social influences & 6 & 2 & 33.3 \\
\hline Past behaviour & 5 & 1 & 20.0 \\
\hline Knowledge & 2 & 1 & $\mathrm{~N} / \mathrm{A}$ \\
\hline Role \& identity & 2 & 0 & $N / A$ \\
\hline Moral norm & I & 0 & N/A \\
\hline Emotion & 1 & 0 & $\mathrm{~N} / \mathrm{A}$ \\
\hline Personal characteristics & I & 1 & $\mathrm{~N} / \mathrm{A}$ \\
\hline Environmental factors & I & 1 & $N / A$ \\
\hline \multicolumn{4}{|l|}{ Prediction of intention } \\
\hline Beliefs about consequences & 79 & 58 & 73.4 \\
\hline Social influences & 75 & 47 & 62.3 \\
\hline Beliefs about capabilities & 65 & 51 & 78.5 \\
\hline Past behaviour & 31 & 14 & 45.2 \\
\hline Characteristics of HP & 29 & 11 & 37.9 \\
\hline Moral norm & 14 & 10 & 71.4 \\
\hline Role \& Identity & 14 & 8 & 57.1 \\
\hline Emotion & 9 & 3 & 33.3 \\
\hline Knowledge & 8 & 1 & 12.5 \\
\hline Environment & 4 & I & 25.0 \\
\hline
\end{tabular}

N/A: not computed because it was not measured at least three times.

compared to smaller samples (behaviour: $\mathrm{Z}=-4.710 ; p<$ 0.0001 ; intention: $Z=-8.643 ; p<0.0001)$. Concerning the psychometric qualities, no difference $(Z=-0.166 ; p>$ $0.05)$ was observed for the prediction of behaviour whereas for the prediction of intention, studies where the information was presented and the psychometric qualities were good, a higher frequency-weighted mean $\mathrm{R}^{2}$ value was observed $(Z=-10.925 ; p<0.0001)$. Finally, concerning the prediction of behaviour, a better frequencyweighted mean $\mathrm{R}^{2}$ was observed when behaviour was selfreported compared to objectively assessed $(Z=9.521 ; p<$ $0.0001)$. In this latter case, the frequency-weighted mean $\mathrm{R}^{2}$ value for the prediction of behaviour varied according to the level of correspondence between intention and behaviour; a better prediction of behaviour was observed when the level of correspondence was appropriate $(\mathrm{Z}=$ 7.993; $p<0.0001)$.

\section{Discussion}

The present study examined the efficacy of studies based on social cognitive theories in explaining intention and predicting the clinical behaviour of healthcare professionals. By means of a systematic review, the overall efficacy was evaluated and the effect of factors that could affect the efficacy of prediction was also examined. Overall, the efficacy of prediction of behaviour was equivalent to values reported in several meta-analyses of the TPB, the most widely used social cognition model of health behaviour. For instance, between $25.6 \%$ and $34 \%$ of explained variance in behaviour was reported for applications of the TPB $[9,99]$. The current frequency-weighted mean $\mathrm{R}^{2}$ of 0.31 for the prediction of healthcare professional' behaviours compares very favourably to these figures. Regarding the prediction of intention, however, the value observed in the present study (59\% explained variance) was higher that the values reported for applications of the ТРB (33.7\% in Conner and Sparks [9], and 40\% in Godin and Kok [99]). A possible explanation for this is that the present review was not limited to the TPB. Other theories were investigated and consequently variables other than those identified in the TPB were considered in the prediction. For instance, role beliefs and moral norm are important variables in Triandis' theory that emerged as substantial determinants of intention.

This systematic review also showed that a number of factors affect the efficacy of prediction of intention/behaviour. On this regard, type of health professionals and behaviour categories, sample size, psychometric qualities, method for assessing behaviour, level of correspondence between the operational definitions of intention and behaviour required special attention. 
Table 3: Model efficacy to predict healthcare professionals' behaviours and intentions according to the type of professional and behaviours

\begin{tabular}{|c|c|c|c|}
\hline Healthcare professionals & Behaviour categories & $\begin{array}{l}\text { Number of } \\
\text { participants } \\
\text { (studies) }\end{array}$ & $\begin{array}{c}\text { Frequency- } \\
\text { weighted mean } \\
\mathrm{R}^{2 *}\end{array}$ \\
\hline \multicolumn{4}{|l|}{ Prediction of behaviour } \\
\hline \multirow[t]{4}{*}{ Physicians } & Clinical practice & $387(4)$ & 0.11 \\
\hline & Compliance with guidelines & $33(1)$ & 0.001 \\
\hline & Counseling & $765(1)$ & 0.40 \\
\hline & Total & $1185(6)$ & 0.28 \\
\hline \multirow[t]{4}{*}{ Nurses } & Clinical practice & $220(3)$ & 0.41 \\
\hline & Compliance with guidelines & $225(2)$ & 0.19 \\
\hline & Documentation & $158(2)$ & 0.09 \\
\hline & Total & $603(7)$ & 0.24 \\
\hline \multirow{3}{*}{ Other professionals } & Clinical practice & $284(1)$ & 0.58 \\
\hline & Counseling & $40(1)$ & 0.33 \\
\hline & Total & $324(2)$ & 0.55 \\
\hline \multicolumn{4}{|l|}{ Prediction of intention } \\
\hline \multirow[t]{6}{*}{ Physicians } & Clinical practice & $2185(11)$ & 0.54 \\
\hline & Acceptance of technologies & I $150(4)$ & 0.68 \\
\hline & Compliance with guidelines & $762(4)$ & 0.50 \\
\hline & Counseling & I I46 (3) & 0.28 \\
\hline & Documentation & $180(2)$ & 0.19 \\
\hline & Total & $5423(24)$ & 0.51 \\
\hline \multirow[t]{5}{*}{ Nurses } & Clinical practice & $4443(21)$ & 0.68 \\
\hline & Acceptance of technologies & $151(1)$ & 0.77 \\
\hline & Compliance with guidelines & $1181(5)$ & 0.62 \\
\hline & Documentation & $108(1)$ & 0.46 \\
\hline & Total & $5883(28)$ & 0.66 \\
\hline \multirow[t]{4}{*}{ Other professionals } & Clinical practice & $2042(6)$ & 0.53 \\
\hline & Compliance with guidelines & $527(\mathrm{I})$ & 0.73 \\
\hline & Counseling & I III (5) & 0.62 \\
\hline & Total & $3680(12)$ & 0.59 \\
\hline
\end{tabular}

Note: Because there were missing data in few publications, total differs from 16 and 72 studies for the behaviour and intention, respectively.

Variations in the efficacy of prediction of intention and behaviour were observed between types of healthcare professionals. In the prediction of behaviour, the best predictive models were observed for healthcare professionals other than physicians and nurses, whereas the best prediction of intention was observed among the nurse samples. Similarly, important variations in explained variance of professionals' behaviours and intentions were observed between behavioural categories. It is not clear what underlies these variations in efficacy of prediction, but one possible explanation could be the nature of the behaviour to be performed and the context of practice. This was particularly evident in prospective studies among physician samples, in which these two elements were defined more vaguely probably because the clinical practice of physician is more difficult to define accurately. This interpretation is further supported by our observation that the operational definitions of intention in terms of action and context for the prediction of behaviour were generally more precise in other healthcare professional samples compared with the studies of physician samples. Given the complexity of clinical-related behaviours, and particularly for diagnostics and treatment decisions, behaviour adoption could be modulated by several aspects of the context, such as patients' acceptability or preference for a given treatment, characteristics of the health problems, new versus usual patients, patients with multiple symptoms, antecedents or counter indications for a given type of medication, etc. Consequently, the accuracy of intention to predict future behaviour is reduced. Obviously, further research should pay more attention not only to the definition of the targeted behaviour, but also to its context of realization. As such, the use of vignettes could be a useful avenue to define more specifically the context of behavioural performance. For instance, Harrell and Bennett [22] successfully used a vignette to predict prescribing behaviour 
Table 4: Model efficacy to predict healthcare professionals' behaviours and intentions according to the methodological qualities of the studies

\begin{tabular}{|c|c|c|}
\hline Characteristic of the studies & $\begin{array}{l}\text { Number of } \\
\text { participants } \\
\text { (studies) }\end{array}$ & $\begin{array}{c}\text { Frequency- } \\
\text { weighted mean } \\
\mathrm{R}^{2}\end{array}$ \\
\hline \multicolumn{3}{|l|}{ Prediction of behaviour } \\
\hline \multicolumn{3}{|l|}{ Sample size } \\
\hline$-N<150$ & $833(12)$ & 0.22 \\
\hline$-N \geq 150$ & $279(3)$ & 0.38 \\
\hline \multicolumn{3}{|l|}{ Psychometric quality } \\
\hline - No information/poor values & $1119(7)$ & 0.31 \\
\hline - Complete information/good values & $993(8)$ & 0.32 \\
\hline \multicolumn{3}{|l|}{ Behavioural measure } \\
\hline - Self-report & I 286 (4) & 0.44 \\
\hline - Objective & $826(\mathrm{II})$ & 0.13 \\
\hline \multicolumn{3}{|c|}{ Level of correspondence for intention-behaviour* } \\
\hline - Poor/unclear & $546(6)$ & 0.10 \\
\hline - Good & 566 (9) & 0.39 \\
\hline \multicolumn{3}{|l|}{ Prediction of intention } \\
\hline \multicolumn{3}{|l|}{ Sample size } \\
\hline$-N<150$ & $3187(34)$ & 0.50 \\
\hline$-N \geq 150$ & $11799(30)$ & 0.61 \\
\hline \multicolumn{3}{|l|}{ Psychometric quality } \\
\hline - No information/poor values & $3112(15)$ & 0.47 \\
\hline - Complete information/good values & II $874(49)$ & 0.62 \\
\hline
\end{tabular}

* The intention-behaviour correspondence was good for all self-reported measurements

Note: Because there were missing data in few publications, total differs from 16 and 72 studies for the behaviour and intention, respectively.

among a physician sample. They were able to explain $26.8 \%$ of variance in a behaviour assessed objectively. Thus, the use of vignettes could help healthcare professionals to better define the context of behavioural performance and formulate their intention more accurately. Consequently, the efficacy of social cognitive theories to understand healthcare professionals' behaviour could be improved and the findings could be more appropriate to inform future interventions.

Other methodological aspects were also scrutinized in the present review, and obviously they require special attention given their significant impact on the efficacy to explain intention and predict behaviour. For instance, when an objective measure of behaviour was obtained, the efficacy of prediction was much lower than when selfreport measures were used. This observation is congruent with the results reported by Armitage and Conner [100] for the prediction of behaviour. They observed a significant difference between the proportion of variance explained when behaviours were observed $\left(R^{2}=0.20\right)$ compared to self-reported $\left(\mathrm{R}^{2}=0.31\right)$. It can be argued that the objective assessment of behaviour is less subject to several biases (including reporting bias) than selfreports and consequently is more accurate in measurement. However, the majority of the studies using an objective measure of behaviour did not comply with the principle of correspondence between intention and behaviour, as recommended by Fishbein and Ajzen [13] (and acknowledged by most theorists in social psychology). Again, the main discrepancies were noted for the action and context dimensions; that is, the action and context mentioned in the statement of intention did not fully correspond to the behavioural measured obtained. For example, in the study by Sauls [30], the intention of intra-partum nurses was formulated with respect to several specific actions related to professional labour support during childbirth. However, the measure obtained as the behavioural outcome was the patients' length of labour. This resulted in a lack of correspondence between what was measured and what was intended. In summary, one cannot eliminate flaws in methods as an explanation for the poor efficacy in prediction when objective measures were taken. This appears to be an important point that will require further investigation.

Another methodological aspect affecting the efficacy in prediction is sample size. A lower prediction was observed among studies with smaller sample sizes. This observation supports the thorough analysis by Rashidian and colleagues [18] who estimated the sample size that should be used for a random survey of prescribing intention and actual prescribing for a study based on the TPB. Based on the variance inflation factor method, they suggested that a sample size of 148 should be recruited. This suggests that studies of healthcare professionals' behaviours should be 
planned in order to recruit the appropriate number of participants. If this condition is not met, the potential to obtain an efficient predictive model is reduced.

The results also indicated that good psychometric values are essential to explain a greater proportion of the intention variance. It has been documented that the reliability of a scale affects its predictive power; poor prediction results from poor reliability [101]. This effect was not observed for the prediction of behaviour, but the number of studies was relatively small compared to the number of studies available for the analysis of intention.

To guide the analysis of the variables measured to predict intention and behaviour, we used the comprehensive approach suggested by Michie and colleagues [8]. This approach was found to be very useful to capture most of the dimensions that were used to study healthcare professionals' behaviours. Notwithstanding the quality of their classification, we added two categories to their method: moral norm and habit/past behaviour. This decision is supported by the finding that moral norm as a single construct was found to be a significant determinant of intention seven out of ten times when assessed. It is also likely that with the addition of studies on the prediction of behaviour, the importance of past behaviour/habit will progressively emerge. This anticipated result is based on the observations of Verplanken and Woods [102] who demonstrated that habitual behaviour performed in a stable context is more difficult to change. Given that many of the behaviours performed by healthcare professionals could be categorized as habitual because they are typically performed in a stable context, this aspect should be documented in future studies. Unfortunately, at this time, it is not possible to verify this assumption as the number of applications was not sufficient.

One of the key questions addressed by this review is which theory or theoretical construct is the most relevant for the study of healthcare professionals' behaviours. Our results suggest that the TPB is an appropriate theory to predict behaviour, whereas Triandis' theory better captures the dynamic underlying intention. Indeed, the two categories of variables predicting behaviour most often (when assessed) were intention and beliefs about capabilities. This latter category includes the concept of perceived behavioural control, one of the TPB determinants of behaviour alongside intention. Concerning the determinants of intention, the situation is more complex, because five categories of variables significantly contributed to its prediction (i.e., most of the time when assessed). These categories of variables were: beliefs about capabilities, beliefs about consequences; moral norm; social influences; and role and identity. According to Triandis' theory, these variables would correspond to facilitating factors, cognitive attitude, moral norm, social norm, and role beliefs, respectively. Finally, even if habit did not emerge as one of the important determinants predicting behaviour, it has been added because according to Weinstein [103] its effect should be controlled in longitudinal studies. Thus, direct links with both intention and behaviour are anticipated. Interestingly, this variable is also included in Triandis' theory. We have illustrated the interrelationship of these variables in the prediction of intention and behaviour in Figure 2. We do not imply that other factors are not important, but it appears from our analysis, that the integration of the variables presented in Figure 2 summarizes the majority of our observations.

A number of limitations should be noted. First, a limited number of studies predicting behaviour were identified. It appears that most of the effort invested was concerned with understanding intention. Not much attention has been given to prospective studies aimed at predicting behaviour. More studies of behaviour prediction are therefore strongly needed to understand which factors underlie the cognitive process of decision-making in clinical-related behaviours. Second, in our analysis of the efficacy of prediction, we did not control for the number of variables included in the predictive models. We acknowledge that this might have inflated the relative performance of some theories over more parsimonious ones.

\section{Conclusion}

In conclusion, this study was the first systematic review aimed at investigating applications of different social cognitive theories for the study of clinical-related behaviours of health professionals. This is an important first step in identifying variables explaining intention and predicting clinical-related behaviours. Nonetheless, a number of

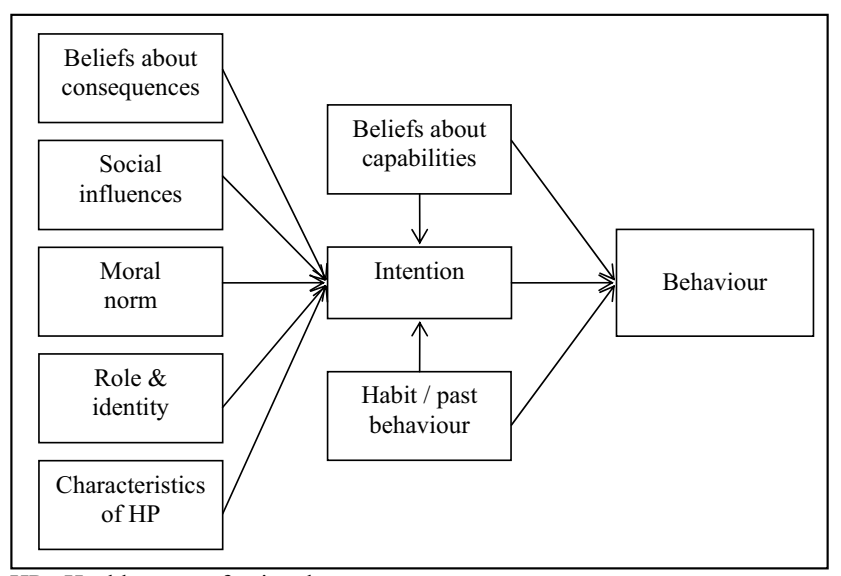

HP : Healthcare professional

\section{Figure 2}

Hypothesized theoretical framework for the study of healthcare professionals' behaviour and intention. 
methodological factors were identified as potential moderators of the efficacy in prediction of studies based on social cognitive theories. Future studies should take into consideration methodological aspects in order to contribute to the development of a significant corpus of data on the clinical behaviours of healthcare professionals. In particular, special care should be given to better define the context of behaviour performance. In addition, we noted that there is an important lack of prospective studies predicting healthcare professionals' clinical-related behaviours; only 16 studies were identified. Thus, there is an urgent need of additional prospective studies based on sound theoretical frameworks. We hope that the information provided in this review of the scientific literature will be useful to researchers in the planning of studies that may lead to improved strategies to change healthcare professionals' behaviours.

\section{Competing interests}

The authors declare that they have no competing interests.

\section{Authors' contributions}

GG, JG and ME conceptualized the review and had regular discussion on this topic in KT ICEBERG meetings. ABG coordinated and performed the acquisition of data as well as the statistical analysis. GG helped conduct the data analysis and interpretation. GG and ABG drafted the manuscript. ME and JG provided critical review on all parts of the manuscript. All authors approved the final version of the manuscript.

\section{Additional material}

\section{Additional file 1}

The search strategy. This table describes the literature search strategy used for this review.

Click here for file

[http://www.biomedcentral.com/content/supplementary/1748-

5908-3-36-S1.pdf]

\section{Additional file 2}

Prospective studies aimed at predicting health professionals' behaviour. This table is the synthesis of data abstraction for studies aimed at predicting healthcare professionals' behaviours.

Click here for file

[http://www.biomedcentral.com/content/supplementary/17485908-3-36-S2.pdf]

\section{Additional file 3}

Studies aimed at predicting health professionals' intentions. This table is the synthesis of data abstraction for studies aimed at predicting healthcare professionals' intentions.

Click here for file

[http://www.biomedcentral.com/content/supplementary/17485908-3-36-S3.pdf]

\section{Additional file 4}

Classification of variables. This table describes the domains of the variables extracted for the review.

Click here for file

[http://www.biomedcentral.com/content/supplementary/17485908-3-36-S4.pdf]

\section{Acknowledgements}

We thank Steve Amireault (SA) for his assistance in data abstraction.

\section{References}

I. Grimshaw JM, Eccles MP, Walker AE, Thomas RE: Changing physicians' behavior: what works and thoughts on getting more things to work. I Contin Educ Health Prof 2002, 22:237-243.

2. Boyce JM, Pittet $D$, Healthcare Infection Control Practices Advisory Committee, HICPAC/SHEA/APIC/IDSA Hand Hygiene Task Force: Guideline for hand hygiene in health-care settings. Recommendations of the healthcare infection control practices advisory committee and the HICPAC/SHEA/APIC/IDSA hand hygiene task force. Society for healthcare epidemiology of america/association for professionals in infection control/infectious diseases society of america. In MMWR Recomm Rep Volume 5I. Issue RR-I6 Atlanta, USA: Centers for Disease Control and Prevention; 2002:I-45.

3. Lenfant C: Shattuck lecture - clinical research to clinical practice - lost in translation? N Engl J Med 2003, 349:868-874.

4. Grol R, Wensing M: What drives change? Barriers to and incentives for achieving evidence-based practice. Med J Aust 2004, I80:S57-60.

5. Grimshaw JM, Shirran L, Thomas R, Mowatt G, Fraser C, Bero L, Grilli $R$, Harvey E, Oxman A, O'Brien MA: Changing provider behavior: an overview of systematic reviews of interventions. Med Care 200I, 39:112-45.

6. Grimshaw JM, Thomas RE, MacLennan G, Fraser C, Ramsay CR, Vale L, Whitty P, Eccles MP, Matowe L, Shirran L, et al:: Effectiveness and efficiency of guideline dissemination and implementation strategies. Int J Technol Assess Health Care 2005, 2 I: I 49- I 49.

7. Grol R, Bosch M, Hulscher M, Eccles M, Wensing M: Planning and studying improvement in patient care: the use of theoretical perspectives. Milbank $Q$ 2007, 85:93-138.

8. Michie S, Johnston M, Abraham C, Lawton R, Parker D, Walker A: Making psychological theory useful for implementing evidence based practice: a consensus approach. Qual Saf Health Care 2005, 14:26-33.

9. Conner M, Sparks P: Theory of planned behaviour and health behaviour. In Predicting health behaviour 2 nd edition. Edited by: Conner M, Norman P. Berkshire: Open University Press; 2005: 170-222.

10. Eccles MP, Hrisos S, Francis J, Kaner EF, Dickinson HO, Beyer F, Johnston M: Do self-reported intentions predict clinicians' behaviour: a systematic review. Implement Sci 2006, I:28.

II. Sheeran P: Intention-behavior relations: a conceptual and empirical review. Eur Rev Soc Psychol 2002, I 2: 1-36.

12. Perkins MB, Jensen PS, Jaccard J, Gollwitzer P, Oettingen G, Pappadopulos E, Hoagwood KE: Applying theory-driven approaches to understanding and modifying clinicians' behavior: what do we know? Psychiatr Serv 2007, 58:342-348.

13. Fishbein M, Ajzen I: Belief, attitude, intention and behavior: an introduction to theory of research Reading, Mass.; Don Mills, On.: Addison-Wesley; 1975.

14. Ajzen I: The theory of planned behavior. Organ Behav Hum Decis Process 1991, 50:179-211.

15. Bandura A: Social Foundations of Thought and Action: a Social Cognitive Theory Englewood Cliffs, N. J.: Prentice-Hall; 1986.

16. Triandis HC: Values, attitudes and interpersonal behavior. In Nebraska Symposium on Motivation Beliefs, Attitudes and Values Volume I. Edited by: Page MM. Lincoln, NE: University of Nebraska Press; 1980:195-259.

17. Fishbein M, Triandis HC, Kanfer FH, Becker M, Middlestadt SE, Eichler A, Baum A, Revenson TA, Singer Jerome E: Factors influencing behavior and behavior change. In Handbook of Health Psychology 
Edited by: Baum A, Revenson T, Singer J. Mahwah NJ: Lawrence Erlbaum Associates; 200I:3-17.

18. Rashidian A, Miles J, Russell D, Russell I: Sample size for regression analyses of theory of planned behaviour studies: case of prescribing in general practice. $\mathrm{Br} J$ Health Psychol 2006, I I:58I-593.

19. Cronbach LJ: Coefficient alpha and the internal structure of tests. Psychometrika I95I, 16:297-334.

20. Eccles MP, Grimshaw JM, Johnston M, Steen N, Pitts NB, Thomas R, Glidewell E, Maclennan G, Bonetti D, Walker A: Applying psychological theories to evidence-based clinical practice: Identifying factors predictive of managing upper respiratory tract infections without antibiotics. Implement Sci 2007, 2:26.

21. Gilomen-Study GS: Predicting managed care prescribing using the theory of reasoned action and the theory of planned behavior. In Ph.D Thesis University of Illinois at Chicago, Health Sciences Center; 1998.

22. Harrell GD, Bennett PD: An evaluation of the expectancy value model of attitude measurement for physician prescribing behavior. J Mark Res 1974, I I:269-278.

23. Lambert BL, Salmon JW, Stubbings J, Gilomen-Study G, Valuck RJ, Kezlarian K: Factors associated with antibiotic prescribing in a managed care setting: an exploratory investigation. Soc $\mathrm{Sci}$ Med 1997, 45: I767-1779.

24. Maue S, Segal R, Kimberlin C, Lipowski E: Predicting physician guideline compliance: an assessment of motivators and perceived barriers. Am J Manag Care 2004, 10:383-39I.

25. Millstein SG: Utility of the theories of reasoned action and planned behavior for predicting physician behavior: a prospective analysis. Health Psychol 1996, 15:398-402.

26. Bernaix LW: Nurses' attitudes, subjective norms, and behavioral intentions toward support of breastfeeding mothers. J Hum Lact 2000, 16:20I-209.

27. Godin G, Naccache H, Morel S, Ébacher MF: Determinants of nurses' adherence to universal precautions for venipunctures. Am J Infect Control 2000, 28:359-364.

28. O'Boyle CA, Henly SJ, Larson E: Understanding adherence to hand hygiene recommendations: the theory of planned behavior. Am J Infect Control 200I, 29:352-360.

29. Renfroe DH, O'Sullivan PS, McGee GW: The relationship of attitude, subjective norm, and behavioral intent to the documentation behavior of nurses. Sch Inq Nurs Pract 1990, 4:47-60.

30. Sauls DJ: Nurses' attitudes toward provision of care and related health outcomes. Nurs Res 2007, 56:1 I7-123.

31. Hoppe C: Predicting health professionals management of obesity. Ph.D Thesis 1999.

32. Quinn R: Attitude, subjective norm, behavioural intention, and patient teaching among nurses. In Ph.D Thesis Temple University; 1996.

33. Farris KB, Schopflocher DP: Between intention and behavior: an application of community pharmacists' assessment of pharmaceutical care. Soc Sci Med 1999, 49:55-66.

34. Mason $\mathrm{HL}$ : Using attitudes and subjective norms to predict pharmacist counselling behaviors. Patient Couns Health Educ 1983, 4:190-196.

35. Wilson CP: Applying the theory of planned behavior to predict and explain school psychologists' use of the consultation model. In Ph.D Thesis The University of Nebraska - Lincoln; 1998.

36. Beatty PC, Beatty SF: Anaesthetists' intentions to violate safety guidelines. Anaesthesia 2004, 59:528-540.

37. Bonetti D, Eccles M, Johnston M, Steen N, Grimshaw J, Baker R, Walker A, Pitts N: Guiding the design and selection of interventions to influence the implementation of evidence-based practice: an experimental simulation of a complex intervention trial. Soc Sci Med 2005, 60:2135-2/47.

38. Bunce $D$, Birdi HS: The theory of reasoned action and the theory of planned behaviour as a function of job control. $\mathrm{Br} J$ Health Psychol 1998, 3:265-275.

39. Busha RAC: Predictors of physician intent to provide preventive reproductive health care to adolescents. In Ph.D Thesis The University of lowa; 1998.

40. Chau P, Y K, Hu PJ-H: Information technology acceptance by individual professionals: A model comparison approach. Decision Sci 200I, 32:699-719.
4I. Conner M, Heywood-Everett S: Addressing mental health problems with the theory of planned behaviour. Psychol Health Med 1998, 3:87-95.

42. Croteau AM, Vieru D: Telemedicine adoption by different groups of physicians. System Sciences, 2002 HICSS Proceedings of the 35th Annual Hawaii International Conference on System Sciences 2002: 1985-1993.

43. Fisher D, Pathak D: Influence of attitudes, normative beliefs, and situational variables on physicians' use of pharmacists as drug information consultants. Am J Hosp Pharm 1980, 37:483-491.

44. Foy R, Walker A, Ramsay C, Penney G, Grimshaw J, Francis ]: Theory-based identification of barriers to quality improvement: induced abortion care. Int J Qual Health Care 2005, 17:| 147-I55.

45. Gagnon MP, Sanchez E, Pons JM: From recommendation to action: psychosocial factors influencing physician intention to use health technology assessment (HTA) recommendations. Implement Sci 2006, I:8.

46. Gagnon M-P, Godin G, Gagné C, Fortin J-P, Lamothe L, Reinharz D, Coultier A: An adaptation of the theory of interpersonal behaviour to the study of telemedecine adoption by physicians. Int J Med Inform 2003, 71:103-II5.

47. Gaither CA, Bagozzi RP, Ascione FJ, Kirking DM: A reasoned action approach to physicians' utilization of drug information sources. Pharm Res 1996, 13:|29|-1298.

48. Godin G, Beaulieu D, Touchette JS, Lambert LD, Dodin S: Intention to encourage complementary and alternative medicine among general practitioners and medical students. Behav Med 2007, 33:67-77.

49. Godin G, Boyer R, Duval B, Fortin C, Nadeau D: Understanding physicians' decision to perform a clinical examination on an HIV seropositive patient. Med Care 1992, 30:199-207.

50. Godin G, Naccache H, Fortin C: Understanding physicians' intention to use a simple infection control measure: Wearing gloves. Am J Infect Control 1998, 26:4|3-4I7.

5I. Hu PJ, Chau PYK, Liu Sheng OR, Tam KY: Examining the technology acceptance model using physician acceptance of telemedicine technology. J Manag Inf Syst 1999, 16:9I-II 2.

52. Jones L, Courneya K, Peddle C, Mackey J: Determinants of oncologist-based exercise recommendations: an application of the theory of planned behavior. Rehab Oncol 2005, 23:3-9.

53. Legare F, Godin G, Ringa V, Dodin S, Turcot L, Norton J: Variation in the psychosocial determinants of the intention to prescribe hormone therapy prior to the release of the women's health Initiative trial: a survey of general practitioners and gynaecologists in France and Quebec. BMC Med Inform Decis Mak 2005, 5:31.

54. Legare F, Graham ID, O'Connor AC, Aubin M, Baillargeon L, Leduc $Y$, Maziade J: Prediction of health professionals' intention to screen for decisional conflict in clinical practice. Health Expect 2007, 10:364-379.

55. Liabsuetrakul T, Chongsuvivatwong $V$, Lumbiganon P, Lindmark G: Obstetricians' attitudes, subjective norms, perceived controls, and intentions on antibiotic prophylaxis in caesarean section. Soc Sci Med 2003, 57:1665-1674.

56. Limbert C, Lamb R: Doctors' use of clinical guidelines: two applications of the theory of planned behaviour. Psychol Health Med 2002, 7:30I-310.

57. Ryu S, Ho SH, Han I: Knowledge sharing behavior of physicians in hospitals. Expert Syst Appl 2003, 25: I 13-122.

58. Sable MR, Schwartz LR, Kelly PJ, Lisbon E, Hall MA: Using the theory of reasoned action to explain physician intention to prescribe emergency contraception. Perspect Sex Reprod Health 2006, 38:20-27.

59. Walker AE, Grimshaw JM, Armstrong EM: Salient beliefs and intentions to prescribe antibiotics for patients with a sore throat. Br J Health Psychol 200I, 6:347-360.

60. Bolman $\mathrm{C}$, de Vries H, Mesters I: Factors determining cardiac nurses' intentions to continue using a smoking cessation protocol. Heart Lung 2002, 31:15-24.

6I. Crawford TE: Factors influencing critical care nurses' involvement with families in the intensive care unit. In M.N Thesis Dalhousie University; 1998.

62. Dilorio C: Neuroscience nurses' intentions to care for persons with HIVIAIDS. J Neurosci Nurs 1997, 29:50-55. 
63. Edwards HE, Nash RE, Najman JM, Yates PM, Fentiman BJ, Dewar A, Walsh AM, McDowell JK, Skerman HM: Determinants of nurses' intention to administer opioids for pain relief. Nurs Health Sci 200I, 3:149-159.

64. Feng JY, Wu YW: Nurses' intention to report child abuse in Taiwan: a test of the theory of planned behavior. Res Nurs Health 2005, 28:337-347.

65. Herbert M, Benbasat I: Adopting information technology in hospitals: the relationship between attitudes/expectations and behavior. Hosp Health Serv Adm 1994, 39:369-383.

66. Jurgens DW: Nurses' intentions to administer morphine for postoperative pain: An application of Ajzen's theory of planned behaviour. In Ph.D Thesis The University of Saskatchewan; 1996.

67. Laschinger HK, Goldenberg D: Attitudes of practicing nurses as predictors of intended care behavior with persons who are HIV positive: testing the Ajzen-Fishbein Theory of Reasoned Action. Res Nurs Health 1993, 16:441-450.

68. Laschinger HK, Goldenberg D, Dal Bello D: Community health nurses' HIV care behavior. I Community Health Nurs 1995, 12:147-159.

69. Lavoie M, Blondeau D, Godin G: Intentions to select a given level of care when confronted with an ethical issue: The impact of a living will. J Appl Soc Psychol 1999, 29:772-785.

70. McKinlay A, Couston M, Cowan S: Nurses' behavioural intentions towards self-poisoning patients: a theory of reasoned action, comparison of attitudes and subjective norms as predictive variables. J Adv Nurs 2001, 34:107-116.

7I. Nash R, Edwards H, Nebauer M: Effect of attitudes, subjective norms and perceived control on nurses' intention to assess patients' pain. J Adv Nurs 1993, 18:94I-947.

72. Payant $L$ : Factors related to childbirth nurses' intentions to provide continuous labour support to women during childbirth. In M.Sc Thesis University of Ottawa; 2006.

73. Puffer $\mathrm{S}$, Rashidian A: Practice nurses' intentions to use clinical guidelines. J Adv Nurs 2004, 47:500-509.

74. Schottle NK: Obstetrical nurses' intentions toward collaborating with midwives. In M.Sc.N Thesis University of Toronto; 1999.

75. Tessaro I, Highriter M: HIV and the work intentions of public health nurses. Public Health Nurs 1994, I I:273-280.

76. Vermette L, Godin G: Nurses' intentions to provide home care: the impact of AIDS and homosexuality. AIDS Care 1996, 8:479-488.

77. Wallace KG, Koeppel K, Senko A, Stawiaz K, Thomas C, Kosar K: Effect of attitudes and subjective norms on intention to provide oral care to patients receiving antineoplastic chemotherapy. Cancer Nurs 1997, 20:34-41.

78. Walsh AM, Edwards HE, Courtney MD, Wilson JE, Monaghan SJ: Fever management: paediatric nurses' knowledge, attitudes and influencing factors. J Adv Nurs 2005, 49:453-464.

79. Waltman NL, Corless IB: Attitudes, subjective norms, and behavioral intentions of nurses toward dying patients and their families. Oncol Nurs Forum 1990, 17:55-60. discussion 60-52

80. Watson PWB, Myers LB: Which cognitive factors predict clinical glove use amongst nurses? Psychol Health Med 200I, 6:399-409.

81. Werner P, Mendelsson G: Nursing staff members' intentions to use physical restraints with older people: testing the theory of reasoned action. J Adv Nurs 200I, 35:784-79I.

82. Whitby M, McLaws ML, Ross MW: Why healthcare workers don't wash their hands: a behavioral explanation. Infect Control Hosp Epidemiol 2006, 27:484-492.

83. Bonetti D, Pitts NB, Eccles M, Grimshaw J, Johnston M, Steen N, Glidewell L, Thomas R, Maclennan G, Clarkson JE, Walker A: Applying psychological theory to evidence-based clinical practice: identifying factors predictive of taking intra-oral radiographs. Soc Sci Med 2006, 63: I889-1899.

84. Daneault S, Beaudry M, Godin G: Psychosocial determinants of the intention of nurses and dieteticians to recommend breastfeeding. Can J Public Health 2004, 95: I5I-I 54.

85. Farris KB, Kirking DM: Predicting community pharmacists' intention to try to prevent and correct drug therapy problems. J Soc Adm Pharm 1995, I 2:64-78.

86. Faulkner G, Biddle S: Predicting physical activity promotion in health care settings. Am J Health Promot 200I, 16:98-106.
87. Foy R, Bamford C, Francis J], Johnston M, Lecouturier J, Eccles M, Steen $N$, Grimshaw J: Which factors explain variation in intention to disclose a diagnosis of dementia? A theory-based survey of mental health professionals. Implement Sci 2007, 2:3I.

88. Herbert KE, Urmie JM, Newland BA, Farris KB: Prediction of pharmacist intention to provide Medicare medication therapy management services using the theory of planned behavior. Res Social Adm Pharm 2006, 2:299-314.

89. Jenner EA, Watson PWB, Miller L, Jones F, Scott GM: Explaining hand hygiene practice: an extended application of the Theory of Planned Behaviour. Psychol Health Med 2002, 7:3 I I-326.

90. Kittisopee $\mathrm{T}$ : The influences of personality, social cognition, and environmental factors on pharmaceutical care. In Ph.D Thesis The University of lowa; 200I.

91. Klaybor GR: An application of the theory of planned behavior on clinical social workers' utilization of the DSM-IV: An exploratory study. In Ph.D Thesis University of Houston; 1998.

92. Levin PF: Test of the Fishbein and Ajzen models as predictors of health care workers' glove use. Res Nurs Health 1999, 22:295-307.

93. Pessoa-Silva CL, Posfay-Barbe K, Pfister R, Touveneau S, Perneger TV, Pittet $D$ : Attitudes and perceptions toward hand hygiene among healthcare workers caring for critically ill neonates. Infect Control Hosp Epidemiol 2005, 26:305-3II.

94. Walker A, Watson M, Grimshaw J, Bond C: Applying the theory of planned behaviour to pharmacists' beliefs and intentions about the treatment of vaginal candidiasis with non-prescription medicines. Fam Pract 2004, 2 1:670-676.

95. Godin G, Naccache H, Brodeur JM, Alary M: Understanding the intention of dentists to provide dental care to $\mathrm{HIV+}$ and AIDS patients. Community Dent Oral Epidemiol 1999, 27:221-227.

96. Blackman D: Operant conditioning: an experimental analysis of behaviour London: Methuen; 1974.

97. Davis FD: Perceived Usefulness, Perceived Ease of Use, and User Acceptance of Information Technology. MIS Quarterly 1989, 13:319-340.

98. De Vries $\mathrm{H}$, Mudde A: Predicting stage transitions for smoking cessation applying the attitude-social influence-efficacy model. Psychol Health 1998, 13:369-385.

99. Godin G, Kok G: The theory of planned behavior: a review of its applications to health-related behaviors. Am J Health Promot 1996, I 1:87-98.

100. Armitage CJ, Conner M: Efficacy of the theory of planned behaviour: a meta-analytic review. BrJ Soc Psychol 200I, 40:47I-479.

101. Valois P, Godin G: The importance of selecting appropriate adjective pairs for measuring attitude based on the semantic differential method. Quality and Quantity 1991, 25:57-68.

102. Verplanken B, Wood W: Interventions to Break and Create Consumer Habits. J Public Policy Mark 2006, 25:90-103.

103. Weinstein ND: Misleading tests of health behavior theories. Ann Behav Med 2007, 33:1-10.

Publish with Bio Med Central and every scientist can read your work free of charge

"BioMed Central will be the most significant development for disseminating the results of biomedical research in our lifetime. "

Sir Paul Nurse, Cancer Research UK

Your research papers will be:

- available free of charge to the entire biomedical community

- peer reviewed and published immediately upon acceptance

- cited in PubMed and archived on PubMed Central

- yours - you keep the copyright 